\begin{tabular}{|c|c|c|}
\hline$A$ & $\begin{array}{l}\text { European Association for the } \\
\text { Development of Renewable Energies, Environment } \\
\text { and Power Quality (EA4EPQ) }\end{array}$ & $\begin{array}{l}\text { International Conference on Renewable Energies and Power Quality } \\
\text { (ICREPQ'12) } \\
\text { Santiago de Compostela (Spain), 28th to 30th March, } 2012\end{array}$ \\
\hline
\end{tabular}

\title{
Effects of the Mutual inductances on the Switched Reluctance Machines
}

\author{
${ }^{1,3}$ A. Fleury, ${ }^{1}$ R. J. Dias, ${ }^{1}$ W. R. H. Araújo, ${ }^{2}$ A. W. F. V. Silveira, ${ }^{2}$ D. A. Andrade, ${ }^{3}$ G. C. Ribeiro \\ ${ }^{1}$ Pontifícia Universidade Católica de Goiás, ${ }^{2}$ Universidade Federal de Uberlândia, ${ }^{3}$ Universidade Estadual de Goiás, \\ Rua São Luis, 634, CEP 74460 210, Jardim Petrópolis, Goiânia, Goiás, Brasil \\ Phone: +55 146232975775 \\ afleury@terra.com.br
}

\begin{abstract}
There are many studies which discuss the mutual inductances in the Switched Reluctance Machine SRM. Most of these studies said that the influence of inductance is negligible. In this paper the influences of those inductances are analyzed. This work presents experimental measures and analysis of these quantities on prototypes of SRM with various settings aiming to contribute to the knowledge of the subject. The variations of the inductance profile due to the current in the active phase, the angular position of the rotor and saturation are taken into account. Surfaces are presented to summarize the behavior of the self inductance and of the mutual inductances gotten from different machines. It is presented the simulation of the SRM in generator mode taking into account the mutual inductances. The results are presented and discussed conclusively, and then some propositions are made. The results presented here reveal the relative dimension and the influence of the mutual inductances and show that they have the potential to indicate the position of the rotor of the machine, thus avoiding the use of electronic sensors allowing sensorless techniques. Furthermore, this article highlights the importance of considering the mutual inductances in the design, mathematical modeling and simulation of SRM in order to improve de machine performance.
\end{abstract}

\section{Key words}

Math modeling, Mutual inductances, Self inductance, Switched Reluctance Machine.

\section{Introduction}

The Switched Reluctance Machine - SRM attracted the scientific community from nineties due to the U.S. Air Force More Electric Aircraft Program. It means to replace hydraulic, pneumatic and mechanical devices by electric power to increase the reliability of the aircraft. Indeed an engine directly coupled to the turbine shaft adds simplicity and robustness to electromechanical conversion processes. The SRM has no rotor coils and behaves well under variable speed and extra-high speed [1]. Thus, it is considered as starter-generator coupled to the shaft of an internal combustion engine to provide starting torque and feed electrical loads. As a result of pulleys and belts are eliminated, reducing fuel consumption. On the other hand, due to worldwide demand for alternative and renewable energy, after testing, the Switched Reluctance Generator - SRG is considered promising for applications in wind energy. There are also studies for its use in diverse fields such as electric vehicles or hybrid, in rural electrification or as a battery charger self-excited (standalone). In other experiments, the SRM was particularly effective for fractional power loads [2].

This paper continues the research on the effects of mutual inductances $[1,3]$ that is an aspect not yet consolidated in the scientific community. The fact is that they exist and affect the machine performance. The question is whether or not its effect must be taken into account. The results presented here reveal the relative dimension of the mutual inductances and show that they have the potential to indicate the machine rotor position, thus avoiding the use of electronic sensors allowing sensorless techniques. Furthermore, this article highlights the importance of considering the mutual inductances in the design, mathematical modeling and simulation of SRM in order to increase the machine performance.

This matter concerning the mutual inductances in the switched relucatance machine is focused in some relevant articles as [5] and [6].

\section{Math modeling}

\section{1 - Nomenclature}

$\begin{array}{ll}L & \text { Inductance. } \\ i & \text { Phase current. } \\ \theta & \text { Instantaneous angular position of the rotor. } \\ n & \text { Number of phases of the machine. } \\ j & \text { Order of a phase of the machine. } \\ R & \text { Resistance of a phase coil. } \\ v & \text { Voltage of a phase coil. } \\ \omega & \text { Rotor angular speed. } \\ C_{m} & \text { Mechanical torque. } \\ C_{\text {emag }} & \text { Electromagnetic torque. } \\ J & \text { Rotational inertia. } \\ D & \text { Dynamic friction coefficient. } \\ W^{c o} & \text { Co-energy of a phase. }\end{array}$

It will be present a mathematical model for the SRM taking into account the mutual inductances and saturation effects. This procedure is taken because the inductance 
depends on the constructive parameters of the machine besides angular rotor position and current as well.

In order to obtain an equation for the circuit of the phase $j$, consider the self and the mutual inductances of the phase coil, depending on rotor angular position $(\theta)$ and on the current in that phase coil $\left(i_{j}\right)$. This coil has an internal resistance $\mathrm{Rj}$. Then the voltage at the terminals of the coil is given by:

$$
v_{j}=R_{j} i_{j}+\frac{d}{d t}\left(L_{j j} i_{j}+\sum_{k=1}^{F} L_{j k} i_{k}, j \neq k\right)
$$

with $j$ ranging from 1 to $n$. Here $L_{j k}=L_{k j}, j \neq k$, is the mutual inductance between phases $j$ and $k$, and $L_{j j}$ is the self inductance of the phase $j$.

Equation (1) allows writing a set of non linear differential equations:

$$
\begin{aligned}
& {\left[\begin{array}{c}
v_{1} \\
v_{2} \\
v_{n}
\end{array}\right]=\left[\begin{array}{cccc|c}
R_{1}+\omega \frac{\partial L_{11}}{\partial \theta} & \omega \frac{\partial L_{12}}{\partial \theta} & \omega \frac{\partial L_{1 n}}{\partial \theta} & i_{1} \\
\omega \frac{\partial L_{21}}{\partial \theta} & R_{2}+\omega \frac{\partial L_{22}}{\partial \theta} & \omega \frac{\partial L_{2 n}}{\partial \theta} & i_{2} \\
\dot{L}_{n 1} & \omega \frac{\partial L_{n 2}}{\partial \theta} & \cdot & R_{n}+\omega \frac{\partial L_{n n}}{\partial \theta} & i_{n}
\end{array}\right]+} \\
& +\left[\begin{array}{cccc}
L_{11} & L_{12} & \cdot & L_{1 n} \\
L_{21} & L_{22} & \cdot & L_{2 n} \\
i_{1} \\
i_{21} \\
L_{n 1} & L_{n 2} & \cdot & L_{n n} \\
\vdots \\
i_{n}
\end{array}\right]
\end{aligned}
$$

where $\omega=d \theta / d t$

Equation (2) describes the electromagnetic behavior of the SRG. The mechanical torque depends on the co-energy of the phases, on the rotational inertia and also depends on the dynamic friction coefficient. Including the mechanical relations equation (2) becomes:

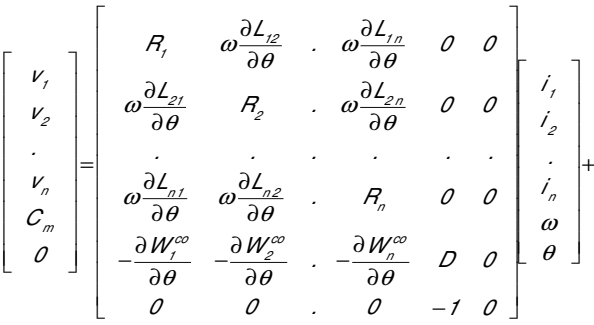

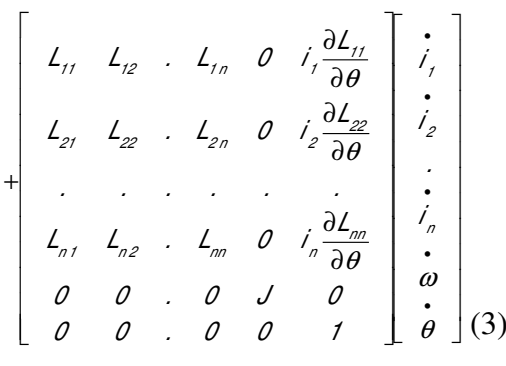

Now let $[\mathrm{V}],[\mathrm{R}],[\mathrm{I}],[\mathrm{L}]$ and $[I]$ be the matrices in the order they appear in (3), then:

$$
\dot{[}]=[\mathrm{L}]^{-1}[\mathrm{~V}]-[\mathrm{L}]^{-1}[\mathrm{R}][\mathrm{I}]
$$

This equation completely describes the state of each phase of the machine at any time. It can be solved by iterative numerical computational methods.

\section{Measurements of self and mutual inductances}

Scientific papers dealing with the SRM disregard the mutual coupling between phases. According to the authors the mutual inductances can be disregarded in the design of the machine, in the simulations and evaluations of the performance of the prototypes, with no important impact on results because they are small, approximately 1 percent of the self inductance. But this paper presents studies where the mutual inductances are greater than $1 \%$, enlarging its relevance. So the relationship between the self and mutual inductances is the point.

From (1), under certain circumstances the self inductance can be written as:

$$
L_{i j}=\frac{1}{\omega_{e}} \cdot \sqrt{\frac{V^{2}}{I^{2}}-R^{2}}
$$

In this case all the phase coils are open, except for phase $j$. The rotor is blocked. Alternate current of electrical frequency $\omega_{e}$ excites the active phase. $V$ and $I$ are the rms values for the active phase voltage and current respectively.

For the mutual inductances, its equation can be written as:

$$
L_{k j}=L_{j k}=L_{j j} \cdot \frac{v_{k}}{v_{j}-R_{j} \cdot i_{j}}
$$

where $L_{k j}$ is the mutual inductance between the phases $k$ and $j$, respectively. $L_{j j}$ is the self inductance of the active phase, $v_{k}$ is the induced voltage in the phase $k, v_{j}$ is the voltage on the active phase, $R_{j}$ is the resistance of this phase and $i_{j}$ is its current. Thus, the relationship between the mutual and self inductances is given by:

$$
\frac{L_{k j}}{L_{j j}}=\frac{v_{k}}{\left(v_{j}-R_{j} \cdot i_{j}\right)}
$$

This ratio varies depending on the current and the instantaneous angular position of the rotor.

The presented method to determine the mutual inductances from the experimental data is applied when the rotor is locked and the phases are open circuited, except the one destined to excite the rotor yoke. This method allows studying the dynamic behavior of the relations between the self inductance and mutual inductances in prototypes.

\section{1 - Experimental measures of the inductances}

The mutual inductances were measured in a SRM with $8 x 6$ topology and in another with $6 x 4$ topology. The data were tabulated and used in a computer model developed with interpolation programs to determine the values of inductances and their derivatives at any locked rotor position for various current values. Both machines have optical sensors to indicate instantaneous rotor position. Fig. 1 shows the test bench. 


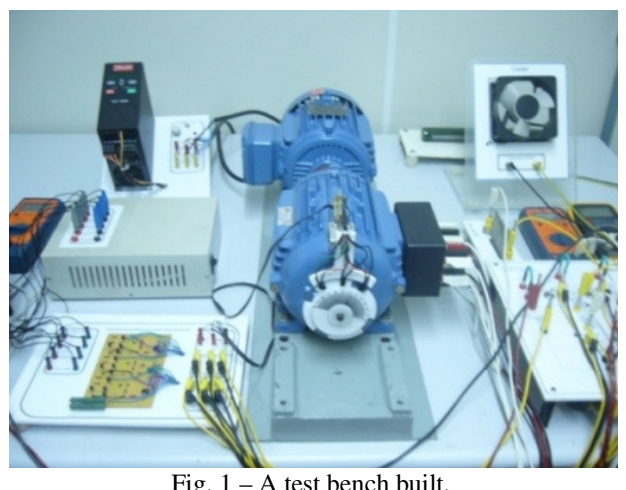

As previously described the procedure used to obtain the values of self and mutual inductances for each rotor position consists on fixing the rotor in a desired position and then energizing the respective phase coil proceeds with the voltage and current measurement of the phase coil. Besides, the induced voltages on the other phases are measured in order to apply equations (5) and (6) aiming calculates the values of self and mutual inductances. With the obtained (calculated) values is possible to trace the profiles of the self and mutual inductances as function of rotor angular position and current.

For the machine $8 \times 6-a$ SRM with 4 phases (A, B, C and D) - the phase D was considered as a reference for the measurements. The current was applied at the phase D and changed from $1 \mathrm{~A}$ to $37 \mathrm{~A}$, with steps of $2 \mathrm{~A}$. The angular position was changed from $0^{0}$ (alignment of poles) up to $30^{\circ}$ (misalignment of the poles), also in increments of two units. This resulted in a database that allows constructing surfaces for experimental inductances.

For a better visualization of the behavior of inductances $L_{i j}(\theta, i)$ of the $8 \times 6$ machine surfaces were constructed from the data collected. These surfaces can be seen in Fig. 2. As shown in equation (3), the values of self and mutual inductances and their derivatives with respect to the angular position of the rotor are required to simulate the behavior of the machine.

Fig. 3 presents the behavior of the inductance of phase $C$ when the measurement procedure was applied at the phase $\mathrm{D}$ (reference phase).

Fig. 4 shows the surface of the mutual inductance $\mathrm{L}_{\mathrm{DB}}$ obtained through the same method of the previous figure.

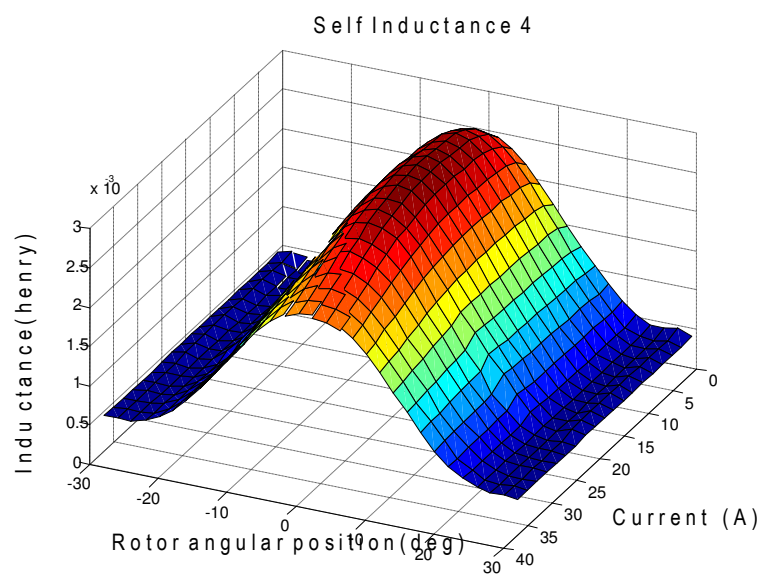

Fig. 2 - Self inductance surface for phase D considering the 8x6 SRM.
Fig. 3 shows the mutual inductance $\mathrm{L}_{\mathrm{DC}}$ obtained from the procedure described in 3.1 .

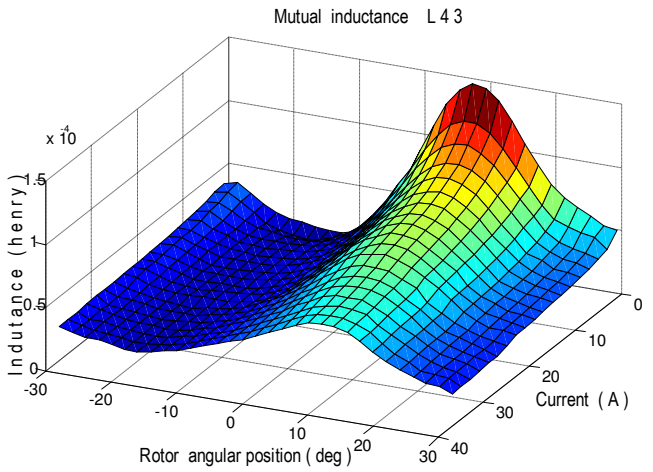

Fig. 3 - Mutual inductance $\mathrm{L}_{\mathrm{DC}}$ considering the $8 \times 6$ SRM.

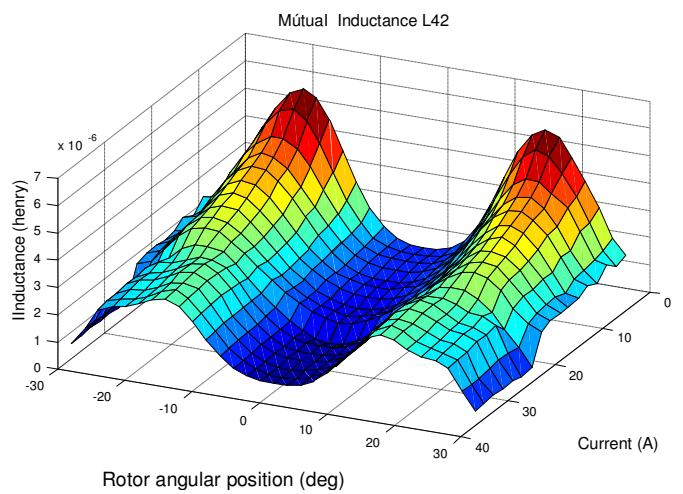

Fig. 4 - Mutual inductance $\mathrm{L}_{\mathrm{DB}}$ considering the $8 \times 6$ SRM.

The mutual inductance $\mathrm{L}_{\mathrm{DA}}$ has the same behavior of the inductance $\mathrm{L}_{\mathrm{DC}}$ (Fig. 3) since these inductances are symmetrical considering the $8 x 6$ topology.

In order to investigate the inductances of the $6 \times 4$ topology machine a second study was conducted with the same procedures with a $6 \times 4$ prototype. Considering a three phase SRM with phases A, B and C, Fig. 5 shows the self inductance of phase $\mathrm{C}$ (took as reference in the measurement procedure).

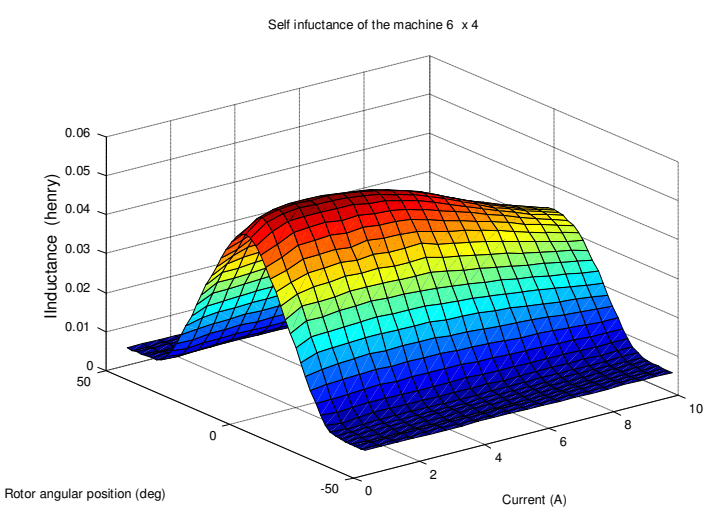

Fig. 5 - Self inductance surface for phase $C$ considering the $6 \times 4$ SRM

The same procedure used for the $8 \times 6$ prototype was applied in the $6 \times 4$ machine. As a three phase machine, the symmetry occurs at the mutual inductances around the reference phase (phase $\mathrm{C}$ ). 
Fig. 6 shows the mutual inductance $\mathrm{L}_{\mathrm{CA}}$ obtained for the 6x4 machine.

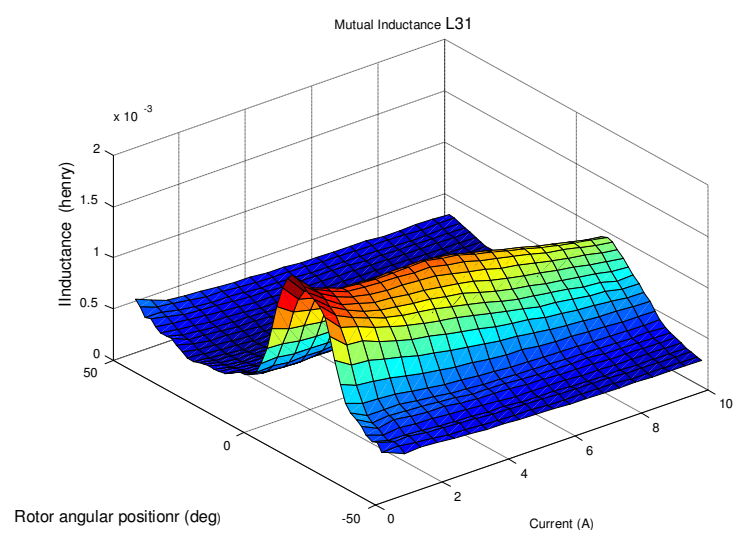

Fig. 6 - Mutual inductance $\mathrm{L}_{\mathrm{CA}}$ considering the $6 \times 4$ SRM.

Through the analysis of the experimental results is possible to verify that the magnitude of the mutual inductance may achieve values that exceed $6 \%$ of self inductance. The next topic presents the simulation results that show the influence of the mutual inductances over the electrical quantities of the SRM.

\section{Simulations}

The mathematical model used to simulate the Switched Reluctance Machine was developed and presented in section 3. The corresponding computing model was developed in MATLAB/SIMULINK environment in order to compare the results with and without the mutual inductances. This model is totally described in [4].

The $6 \times 4$ topology machine was simulated considering the mutual inductances. In a second time they were not. The simulation ran out considering the machine at 1350 RPM speed and with a $48 \mathrm{~V}_{\mathrm{DC}}$ excitation voltage since this value is appointed at automotive applications (electric cars and hybrid vehicles). The simulation time was 5 seconds, time enough for the machine steady state operation. The voltage profile in one of the three phases is presented in Fig. 7, showing its behavior with and without the mutual inductances.

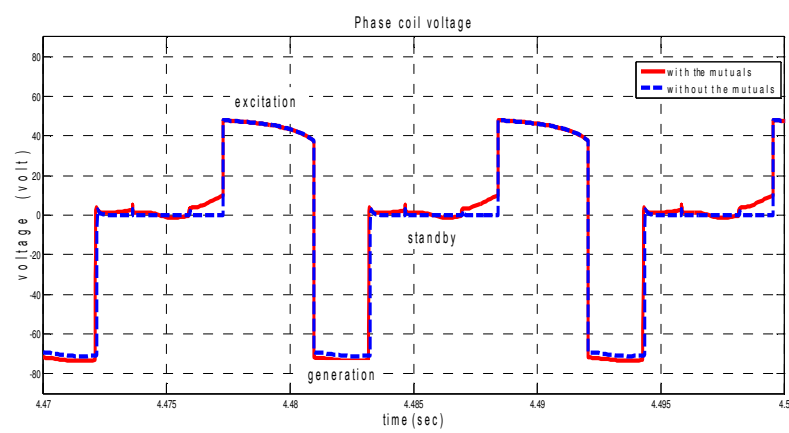

Fig. 7 - Phase voltage profile behavior for a $6 \times 4$ machine with and without the mutual inductances.

Based on equation (2), the phase voltage is:

$$
\begin{aligned}
& v_{1}=R_{1} i_{1}+L_{11} \frac{d i_{1}}{d t}+L_{12} \frac{d i_{2}}{d t}+L_{13} \frac{d i_{3}}{d t}+ \\
& +i_{1} \frac{\partial L_{11}}{\partial \theta} \frac{d \theta}{d t}+i_{2} \frac{\partial L_{12}}{\partial \theta} \frac{d \theta}{d t}+i_{3} \frac{\partial L_{13}}{\partial \theta} \frac{d \theta}{d t}
\end{aligned}
$$

Assuming as $v_{11}, v_{12}, v_{13}, v_{14}, v_{15}, v_{16}$ and $v_{17}$ the terms present in the second member of equation (7), $v_{11}, v_{12}$, and $v_{15}$ are related to the phase coil wich are considered in simulation results shown in Fig. 7 as a straight line (disregarding the mutual inductances). The terms $v_{13}, v_{14}$, $v_{16}$ and $v_{17}$ is from the mutual coupling between phases. These terms consider the mutual inductance influence and the simulation result is shown in Fig. 7 as a dashed line.

The first term $\left(v_{11}\right)$ of the second member (equation 7) is related to the voltage drop at coil resistance. As the resistance is a constant the $v_{11}$ profile is the same of the phase current profile presented in Fig. 8 ( $v_{11}$ is 20 times scaled in order to improve visualization).

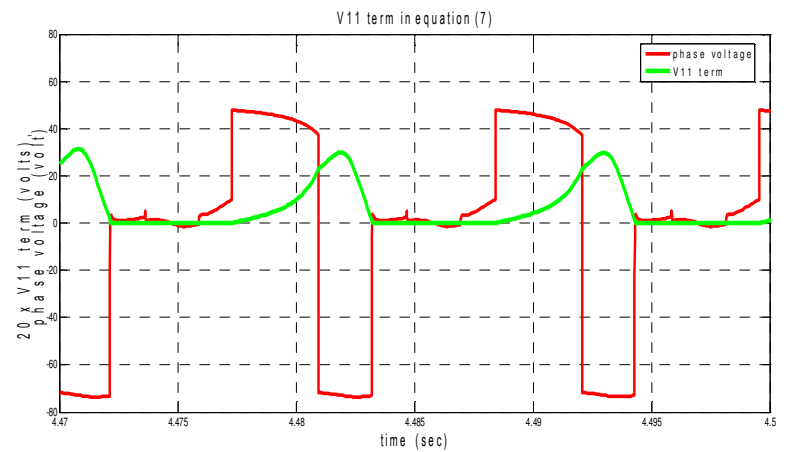

Fig. 8 - Graphical profile of $v_{11}$ term of equation (7) - 20 times scaled.

This term exists during the excitation and generation period of the machine operation but it doesn't when the phase coil is not energized. This occurs because the converter switches are off and the free-wheeling diodes are in reverse polarization (so, the phase current is null). The term $v_{12}$ depends on self inductance $\left(L_{11}\right)$ and phase current derivative. Fig. 9 (scaled for better visualization of self inductance and phase current) shows the profile of the $v_{12}$ term.

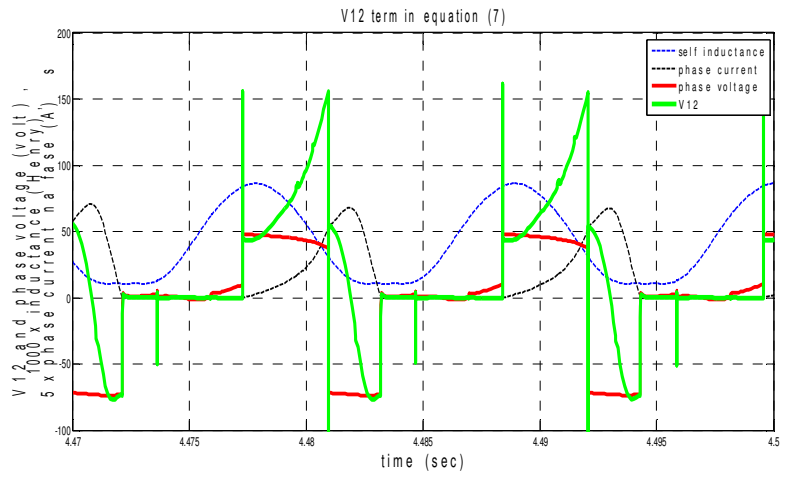

Fig. 9 - Term $v_{12}$, phase current and voltage.

It may be noted that the $v_{12}$ changes at the inflection point of the current curve when its derivative becomes negative. As in $v_{11}$ this term is null when the phase is turned off (closing the converter switches). 
The term $v_{15}$ (which also corresponds to self inductance as well as $v_{11}$ and $v_{12}$ ) is shown in Fig 10.

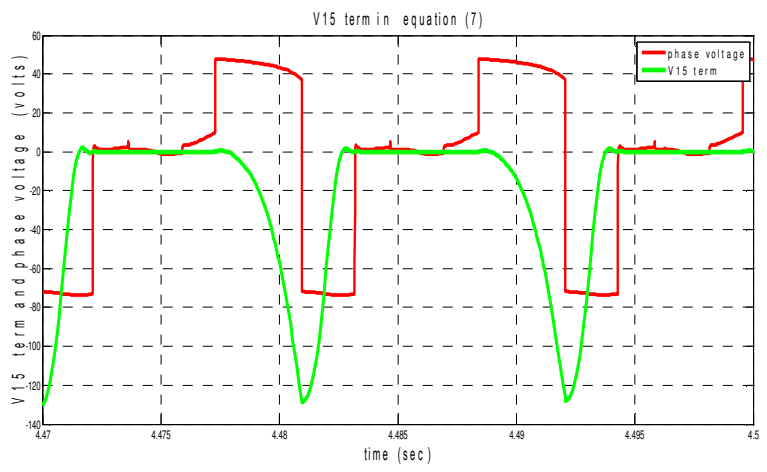

Fig. $10-$ Term $v_{15}$ and phase voltage.

The angular speed and current are always positive, so, the sign of this term is derived from the sign of the selfinductance relative to angular speed. As the literature records, the SRM generate power when the phase is energized in negative derivative of inductance. Because this, the $v_{15}$ profile is negative. This term gets null value when the converter switches are off and when phase current is also null.

The terms $v_{11}, v_{12}$, e $v_{15}$ (previously analyzed) don't depend directly on mutual inductances. Besides, it may be observed that terms $v_{11}, v_{12}$, e $v_{15}$ influences the voltage during the excitation and generation periods, but there is no interference when the converter switched are off.

Fig. 11 shows the term $v_{13}$ compared with phase voltage.

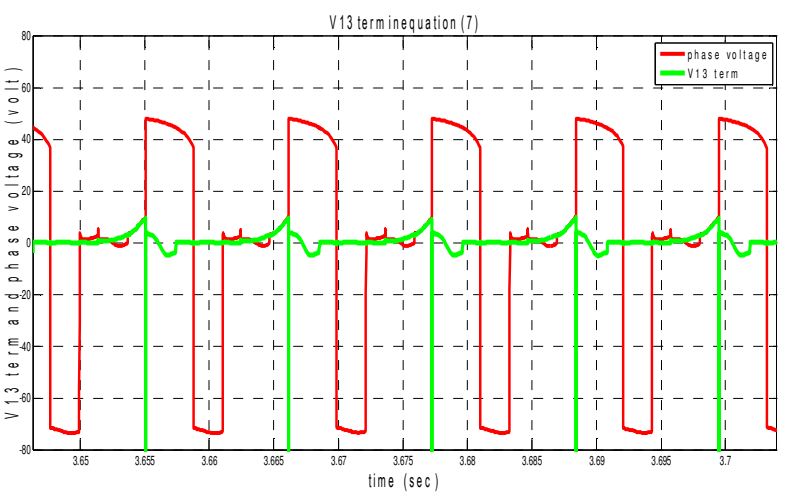

Fig. 11 - Term $v_{13}$ and voltage on the phase coil.

The term $v_{13}$ influences the phase voltage when the converter switches are off and during the excitation period, but it seems to have little or none interference on phase voltage during the excitation period. Indeed, the terms that depends on current of the next phase to be energized (considering the machine operation) like $v_{13} e v_{16}$ induce voltage on the reference phase during the excitation period and when the converter switches are off. Also, the terms that depend on current of the previous phase $\left(v_{14}\right.$ e $\left.v_{17}\right)$ induce voltage during the generation period and when the converter switches are off.

In the same way, Fig. 12 compares the term $v_{14}$ with phase voltage.

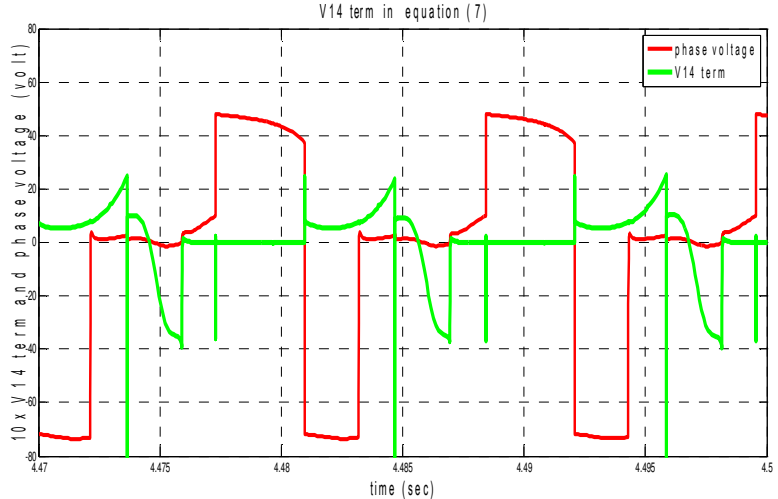

Fig. $12-$ Term $v_{14}$ and phase voltage.

The term $v_{14}$ influences the voltage during generation period and when the converter switches are off and has no interference during the excitation period.

The terms $v_{16}$ and $v_{17}$ are compared to coil voltage in figures 13 and 14, respectively.

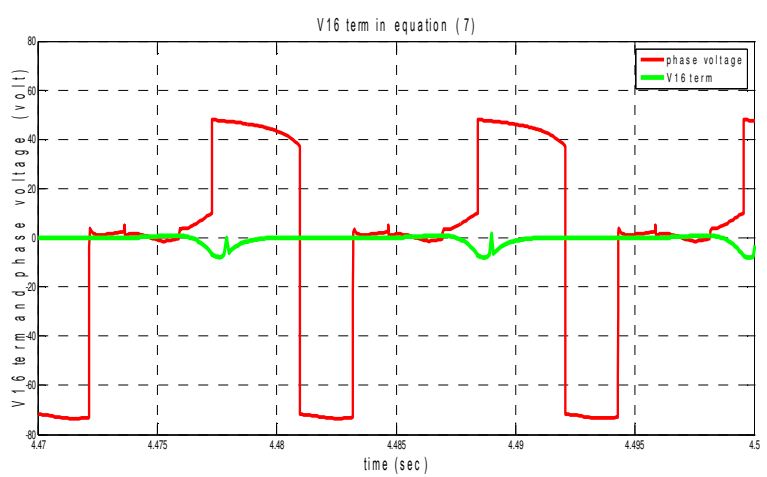

Fig. $13-$ Term $v_{16}$ and phase voltage.

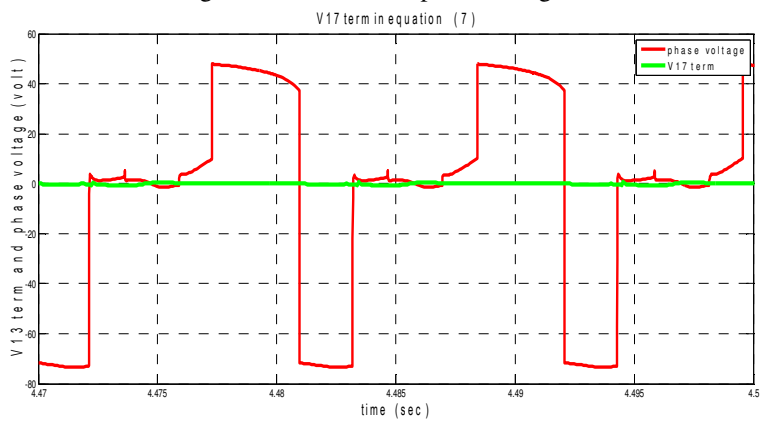

Fig. $14-$ Term $v_{17}$ and phase voltage.

These are the terms that depend on mutual inductance derivative $\left(L_{12}\right.$ e $\left.L_{13}\right)$. The term $v_{15}$ depend on self inductance derivative. These three terms $\left(v_{15}, v_{16}\right.$ and $\left.v_{17}\right)$ composes part of equation (7) wich depends on angular speed. Thus, the phase voltage variation related to the angular speed also depends on mutual inductances behavior.

Figures 15 and 16 synthesize the comparison between simulation results when the mutual inductances are considered and when they don't (considering generator operation). 


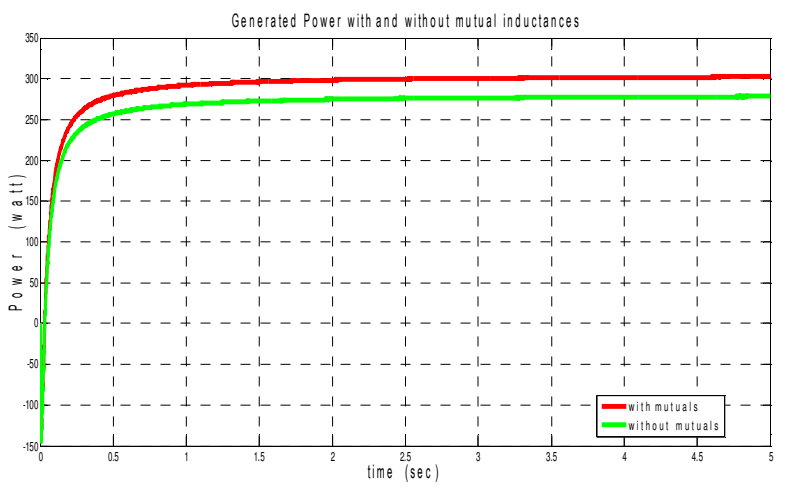

Fig. 15 - Power generated by the SRG (5 seconds simulation time) with and without mutual inductances.

Using the inductances experimental results, there is an expectation about a greater power generation when the mutual inductances are considered. The difference is about 302 watts against 278 watts in the power generated by the machine, wich corresponds an $8,6 \%$ deviation. The deviation magnitude represents a value that points to the mutual inductances consideration. Besides, computer simulation corresponds to the initial process of machine manufacturing. Thus, the correct computing model can achieve improved values for the machine design.

The 8x6 machine was also simulated with and without the mutual inductances considering the previous behaviors shown in figures 2, 3 and 4 . The results was verified and they show similar results related to the $6 \times 4$ machine. Fig. 16 shows the power generated by the $8 \times 6$ machine when the mutual inductances are considered and when they don't.

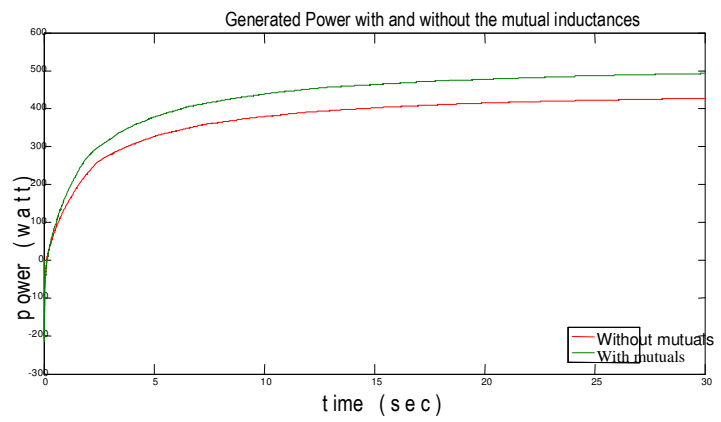

Fig. 16 - Power generated by the $8 \times 6$ machine with and without the mutual inductance.

The deviation was 426,6 watts against 491,5 watts wich corresponds a variation of $15,2 \%$ when the mutual inductances are considered.

\section{Conclusion}

This paper presented an analysis about the mutual inductances of Switched Reluctance Generators.

Mutual inductances profiles were presented pointing that they magnitude is greater than expected, contradicting previous related studies.

The power generated showed an increase of $8,6 \%$ in the simulation results of the $6 \times 4$ topology machine, while the $8 \times 6$ machine simulation resulted in an increase of $15,2 \%$ in the power generated. Thus, considering mutual inductances of Switched Reluctance Machines (operating as generator) results in optimized designs and simulations. This is an important point considering simulation as an initial step of machine manufacturing.

The graphical results presented in figures 7 through 14 points that mutual inductances cause a coupling between machine phases influencing the phase's voltages waveforms. Thus, this behavior can be used in order to implement sensorless techniques despising optical sensors, wich is an exemple of application.

Once there is not a direct method to present experimental results that confirm the increasing in power generation when mutual inductances are taken into account, this study is a step toward new understanding of dynamic behavior of the Switched Reluctance Machine operating as generator. Due to the inner features of the inductances, conclusions about them depend on the configurations of the machine tested, but not depend on its dimensions, and so, the results presented here, gotten from two machines of $1 \mathrm{HP}$ class should be valid for larger machines.

\section{Acknowledgement}

The authors thank Universidade Estadual de Goiás, Universidade Federal de Uberlândia and Pontifícia Universidade Católica de Goiás.

\section{References}

[1] Dias, R.J., Coelho, A., Fleury, A.V.S., "About phases dependence in a switched reluctance generator", ICREPQ 2008 - International Conference on Renewable Energies and Power Quality, electronic midi records, March, 11-14, 2008; in: Renewable Energy and Power Quality Journal, ISSN 2172038X, March 2008 edition.

[2] Andrade, D. A., Costa, R.S., Teixeira, R.S., Fleury, A.V., "Energy Efficiency for Fractional Power Loads", IEEE Industry Application Society Magazine, vol 12, num 6, November/December 2006, pp. 12-20, ISSN 1077-2618.

[3] Fleury, A.V.S., Andrade, D.A., Siveira, A.W.F.V., "Experimental Measurement and Analysis of the Self and Mutual Inductances in Two Different Switched Reluctance Machines", International Conference on Renewable Energies and Power Quality, 2010, Granada - Spain. Record of the ICREPQ 2010, 2010; in: Renewable Energy and Power Quality Journal, April 2010 edition.

[4] Dias, R. J., Andrade, D. A., Cabral, L. G., Silveira, A. W. F. V., Silveira, A. F. V., Gomes, L. C., Bissochi, C. A., Modeling, simulation and Comparative Study Between a Single-Phase Switched Reluctance Machine (6x6) and a ThreePhase Switched Reluctance Machine, in: Renewable Energy and Power Quality Journal, No.9, 12th May 2011. RE\&PQJ-8 ISSN 2172-038X.

[5] de Paula, P.P.; da Silva, W.M.; Cardoso, J.R.; Nabeta, S.I., Assessment of the Influences of the Mutual Inductances on Switched Reluctance Machines Performance, in: Electric Machines and Drives Conference, 2003. IEMDC'03. IEEE International vol 3, page(s): $1732-1738$.

[6] Krishnamurthy, M.; Fahimi, B.; Edrington, C.S.; On the Measurement of Mutual Inductance for aSwitched Reluctance Machine, in: Power Electronics Specialists Conference, 2006. PESC'06, 37th IEEE, Page(s): 1 - 7. 